\title{
A comparison of women's expectations of labour and birth with the experiences in primiparas and multiparas with normal vaginal delivery
}

\section{Pirdel $\mathrm{M}^{1}$, Pirdel L ${ }^{2}$}

${ }^{1}$ Manijeh Pirdel, M.Sc of Midwifery, Department of Midwifery, Astara Branch, Islamic Azad University, Astara, Iran; ${ }^{2}$ Leila Pirdel, Assistant Professor, Department of Medical Sciences, Ardabil branch, Islamic Azad University, Ardabil, Iran.

\begin{abstract}
Background: Maternal childbirth expectations play an important role in determining a woman's response to her childbirth experience. Women need to be helped to develop realistic and positive expectations and identify the factors that influence these expectations.

Objective: The aim of this study was to compare woman's expectations and experiences of childbirth.

Methods: This descriptive-comparative study was carried out in Tabriz Alzahra Hospital from 2006 to 2007. For this purpose, a total of 600 primiparas and multiparas women who were candidates for vaginal delivery, were randomly selected and interviewed. The data were collected by questionnaire.

Results: Comparison of the means of mothers expectation and experience of labor and birth between the two groups demonstrated a statistically significant difference $(p<0.05)$. The findings indicated a number of differences exist between primiparas and multiparas women in relation to expectations and experiences of birth when compare two groups. The majority of women had negative expectations and experiences of childbirth.

Conclusion: The evaluation and understanding of birth expectations and experiences as positive and negative is priority of maternity system. Antenatal educators need to ensure that pregnant women are appropriately prepared for what might actually happen to limit this expectation-experience gap. Health-care providers should improve the quality of antenatal care which can change negative childbirth expectations and experiences of women.
\end{abstract}

Key words: Childbirth expectation, Childbirth experience, Labor, Multiparas, Primiparas

\section{INTRODUCTION}

iving birth is a complex event ${ }^{1}$. A relatively long $\mathcal{J}$ interval from conception to delivery can cause expectations about the birth experience ${ }^{2}$.

The word expectations defined as "an expectant mental attitude". It includes the positive and negative beliefs, attitudes and perceptions ${ }^{3}$. Childbirth expectations play an important role in the women's response to the birthing experience and postpartum period. It has been suggested that the similarity between a woman's expectations and her experience of childbirth may affect their wellbeing and satisfaction of childbirth ${ }^{4-10}$.

Address for correspondence

Manijeh Pirdel

Department of Midwifery, Astara Branch,

Islamic Azad University, Astara, Iran

E-mail: pirdelm@yahoo.com
Woman's ability to meet the majority or at least the most important of their childbirth expectations can form the perception of women about childbirth experience ${ }^{11}$. Some expectations may help a woman to cope successfully with labor while others may be unable to cope $^{12}$. The desire for caesarean section in subsequent pregnancies may be attributed to a negative previous birth experience ${ }^{6-10}$.

All women seem to develop expectation of childbirth and the kinds of expectations vary among women ${ }^{13}$. Studies showed both positive and negative expectations of birth can influence the birth experience ${ }^{14-15}$. Different effects may be related to different aspects of expectations such as emotions, control, pain, and obstetric events ${ }^{16}$. Previous experience or some degree of knowledge requires determining the realistic or practical outcome of expectations. However, the improvement of expectation can develop by new information and experience ${ }^{17}$. 
It has been examined whether expectations differ for women. It seems that multiparas would have different expectations due to previous experience of birth as compared to primiparas women. Interestingly, studies have found no significant differences between primiparas and mulitparas in the different variables of expectations except for the variables of body control in labor over staff actions and involvement in decision making ${ }^{18}$.

Childbirth is a stressful event for many women who had no preparation for childbirth ${ }^{19}$. All the childbirth information received from different sources like prenatal education, previous birth experience, doctor, friends, mothers and media contribute to the formation of the beliefs, resulting in woman's expectations when they give birth ${ }^{3}$. Expectations and experiences of women who did not attend in prenatal preparation programs remain unchangeable ${ }^{2}$.

A woman's attitude toward labor pain is influenced by various factors ${ }^{20}$. One of the most important psychological factors influencing labor pain is realistic and unrealistic expectations of mother regarding the labor pain and the sense of losing control during pain intensity 9, 19, 21-22. It has been shown that mothers who have more realistic expectation may experience less labor pain, diminished disappointment and a sense of failure than mothers who have unrealistic expectations ${ }^{23}$.

The positive expectations may result in positive childbirth which is experienced and vice versa9, $9^{9,15,8}$. When the actual event was experienced by the pregnant woman, this might be in accordance with her expectations or significantly different from her expectations ${ }^{3}$. Comparison of women's expectations and the actual experience of labor pain have shown that a difference existed. Studies have indicated that women usually predict labor process to be very painful. Moreover, childbirth expectations play a role in the establishment and development of women's coping with labor ${ }^{2,9,12,19}$.

Some studies have addressed women's views and expectations of childbirth including pain management, medical intervention, social support, expectations about baby and women's behavior when labor intensified ${ }^{7}, 10$, $18,24-26$.

The purpose of this study was to compare and evaluate what aspects of labor and delivery women describe as different from or the same as their expectations. If major differences exist between many women's expectations and the actual events of birth, women need to be helped to develop realistic and positive expectations and prepare for unexpected events.

It is hoped that this research will help Iranian and others women to meet the challenges of childbirth with positive expectations and to be more satisfied with their childbirth experiences.

\section{METHODS}

The present descriptive-comparative study was carried out on 300 primiparas and 300 multiparas women, who had normal vaginal deliveries in Tabriz Alzahra general governmental hospital from 2006 to 2007. The subjects were selected using a random sampling method. In this study population and sample size were determined. First, each person was numbered. Then, we generated a list of random numbers with a computer program based on acceptance of women in postpartum unit from our population in different shift (morning, evening and night) and those individuals assigned those numbers were the ones we include in the sample. The inclusion criteria included having gestational ages of 37 to 42 week the absence of any verbal communication limitations, no history of psychological problems, the absence of fast (rapid delivery refers to combined First stage and second stage duration is $<2$ hours) or prolonged (i.e. labour that lasts more than 18-20 hours) delivery, the presence of a live and healthy fetus, no need for the use of auxiliary instruments such as forceps or vacuum extraction, no analgesic intake and singleton pregnancy.

The data was collected by two questionnaires. The demographic questionnaire consisted of 40 questions on personal, social and obstetric particulars that had been tailored for the study after an extensive review of the literature. To assess childbirth expectations and experiences, the Expectations of Childbirth Experience questionnaire (ECBE) was used ${ }^{19}$.

This questionnaire asked about the possible events that women think might happen during their labor and birth and subsequent experience of birth on the same scale. The worded either as "do you expect your labor to be..." or "was your labor...".

The Expectations of the Childbirth Experience (ECBE) is a 36-item, 4-point Likert scale that ranged from strongly agree ${ }^{4}$ to strongly disagree ${ }^{1}$ among which 17 items were negatively worded and required reverses scoring. Each participant received a total score on the questionnaire ranging from 36 to 144 . High scores (> 90) indicated positive expectations and experiences of labour and birth process. The instrument consisted 
of five sections: women's expectations of the overall childbirth experience, expectations of the woman's emotional feelings during the first stage of labour, expectations of the birth, expectations related to the baby and expectations related to women's behaviour when labour intensified.

Content and construct validity methods were used to validate the questionnaires. The reliability of questionnaires was tested using test-retest, yielding the following results. A reliability coefficient for the Expectations of the Childbirth Experience questionnaire was 0.83. Visual Analog Scale (VAS) was used to evaluate the intensity of pain. VAS is a 10-centimeter straight line that represents a continuum of pain intensity. Subjects place a mark on the line that represented their level of pain intensity. The distance from the left hand-side quantifies pain level. The test-retest reliability of VAS was high $(r=0.95)^{27}$.

The parturient women were interviewed by researcher during the first and second stages of labor and then after giving birth during 24 hours of postpartum when their physical and emotional condition allowed an interview. Therefore, the data were collected before and after giving birth. Interview was done after signing an informed consent form.

The data were analyzed by WIN/SPSS 14 statistical software. Descriptive statistics such as frequency, mean and standard deviation were used to analyze the data. In addition, independent sample $t$-test was used to compare the means. The relationship between expectations and experiences were expressed using Pearson's correlation coefficient. The level of statistical significance was set at $p<0.05$.

\section{RESULTS}

The mean ages were $22.8 \pm 3.9$ and $27.7 \pm 6.6$ years and the mean weights of the newborns were 3236.5 \pm 4.2 and $3650.03 \pm 3.2$ gram for the primiparas and multiparas. The average duration of the first phase of labor were $5.86 \pm 1.6$ and $4.97 \pm 1.7$ hours and for the second phase of labor were $14.9 \pm 3.4$ minute and $12.7 \pm$ 3.7 minute for the primiparas and multiparas (Table 1). In this study after participants answered the questionnaire, items concerning expectations related to the overall birth experience, feelings during the first stage of labor, the birth experience and expectations related to the baby in primiparas and multiparas women and also expectations related to women's behavior when labor intensified in primiparas, were the highest scored items of the Expectations of the Childbirth Experience (ECBE) and had a mean score $>2$ (Tables 2 and 3 ).
Table 1: Characteristics of participant $(n=600)$

\begin{tabular}{|c|c|c|}
\hline Variables & $\begin{array}{r}\text { Multiparas } \\
\text { N (\%) }\end{array}$ & $\begin{array}{r}\text { Primiparas } \\
\text { N (\%) }\end{array}$ \\
\hline \multicolumn{3}{|l|}{ Age (years) } \\
\hline $15-19$ & $46(15.3)$ & $17(5.7)$ \\
\hline $20-25$ & $185(61.7)$ & $73(24.3)$ \\
\hline $26-30$ & $50(16.7)$ & $111(37)$ \\
\hline $31-35$ & $19(6.3)$ & $90(30)$ \\
\hline $36-40$ & $-*$ & $9(3)$ \\
\hline \multicolumn{3}{|l|}{ Level of education } \\
\hline Illiterate & $21(7)$ & 59 (19.7) \\
\hline Primary & $101(33.7)$ & $69(23)$ \\
\hline Secondary & $64(21.3)$ & $59(19.7)$ \\
\hline High school diploma & $46(15.3)$ & $45(15)$ \\
\hline Above diploma & $53(17.7)$ & $53(17.7)$ \\
\hline University and higher & $15(5)$ & $15(5)$ \\
\hline \multicolumn{3}{|l|}{ Gestational age (weeks) } \\
\hline $37-38$ & $154(51.4)$ & $200(66.7)$ \\
\hline $39-40$ & $100(33.3)$ & $45(15)$ \\
\hline $41-42$ & $46(15.3)$ & $55(18.3)$ \\
\hline \multicolumn{3}{|l|}{ Birth weigh (grams) } \\
\hline$<2500$ & - & $11(3.7)$ \\
\hline $2500-3500$ & $250(83.3)$ & $199(66.3)$ \\
\hline $3500-4500$ & $50(16.7)$ & $90(30)$ \\
\hline \multicolumn{3}{|l|}{ Planned pregnancy } \\
\hline Yes & $291(97)$ & $284(94.7)$ \\
\hline No & $9(3)$ & $16(5.3)$ \\
\hline \multicolumn{3}{|l|}{$\begin{array}{l}\text { Length of first stage of } \\
\text { labour } \\
\text { (hour) }\end{array}$} \\
\hline $2-4$ & 59 (19.7) & $117(39)$ \\
\hline $4-6$ & 119 (39.6) & $139(46.3)$ \\
\hline $6-8$ & $84(28)$ & $15(5)$ \\
\hline $8-10$ & $38(12.7)$ & $29(9.7)$ \\
\hline \multicolumn{3}{|c|}{$\begin{array}{l}\text { Length of second stage of } \\
\text { labour } \\
\text { (minute) }\end{array}$} \\
\hline $5-10$ & $30(10)$ & $136(45.3)$ \\
\hline $10-15$ & $212(70.7)$ & $116(38.7)$ \\
\hline $15-20$ & $49(16.3)$ & $43(14.3)$ \\
\hline $20-25$ & $9(3)$ & $5(1.7)$ \\
\hline \multicolumn{3}{|l|}{$\begin{array}{l}\text { Number of vaginal } \\
\text { examinations }\end{array}$} \\
\hline $1-4$ & $35(11.7)$ & $72(24)$ \\
\hline $5-7$ & $174(58)$ & $126(42)$ \\
\hline 8-11 & $81(27)$ & $73(24.3)$ \\
\hline $12-15$ & $10(3.3)$ & $29(9.7)$ \\
\hline \multicolumn{3}{|l|}{ Childbirth information } \\
\hline Yes & $136(45.3)$ & $122(40.7)$ \\
\hline No & $164(54.7)$ & $178(59.3)$ \\
\hline
\end{tabular}

* - show no frequency for this range. 
Table 2: The $\mathbf{1 0}$ highest scored expectation items of the ECBE scale in primiparas women $(n=300)$

\begin{tabular}{|c|c|c|}
\hline Item & Mean & SD \\
\hline \multicolumn{3}{|l|}{ Expectations related to the overall } \\
\hline \multicolumn{3}{|l|}{ birth experience } \\
\hline Fearful & 3.32 & 0.81 \\
\hline Normal process ${ }^{a}$ & 2.09 & 0.72 \\
\hline Very long & 3.76 & 0.46 \\
\hline Full of surprises ${ }^{a}$ & 3.80 & 0.69 \\
\hline Painful & 3.83 & 0.66 \\
\hline \multicolumn{3}{|l|}{$\begin{array}{l}\text { Expectations related to feelings during } \\
\text { the first stage of labor }\end{array}$} \\
\hline To be afraid & 3.79 & 0.66 \\
\hline To be attached to the baby ${ }^{a}$ & 2.83 & 0.48 \\
\hline \multicolumn{3}{|l|}{$\begin{array}{l}\text { Expectations related to the birth } \\
\text { experience }\end{array}$} \\
\hline Baby's delivery to be understandable ${ }^{a}$ & 2.87 & 0.70 \\
\hline \multicolumn{3}{|l|}{ Expectations related to the baby } \\
\hline Baby to be harmed & 3.64 & 0.48 \\
\hline \multirow{2}{*}{\multicolumn{3}{|c|}{$\begin{array}{l}\text { Expectations related to women's } \\
\text { behavior when labor intensifies }\end{array}$}} \\
\hline & & \\
\hline To cry & 2.91 & 0.43 \\
\hline
\end{tabular}

$\mathrm{ECBE}=$ Expectation of the Childbirth Experience

questionnaire.

aPositive item: the more positive profile of childbirth

expectation.

$\mathrm{SD}=$ Standard Deviation.

Table 3: The 10 highest scored expectation items of the ECBE scale in multiparas women $(n=300)$.

\begin{tabular}{|c|c|c|}
\hline Item & Mean & SD \\
\hline \multicolumn{3}{|l|}{$\begin{array}{l}\text { Expectations related to the overall } \\
\text { birth experience }\end{array}$} \\
\hline Safe ${ }^{a}$ & 2.90 & 0.51 \\
\hline Painful & 3.05 & 0.30 \\
\hline \multicolumn{3}{|c|}{$\begin{array}{l}\text { Expectations related to feelings during } \\
\text { the first stage of labor }\end{array}$} \\
\hline To be very weak & 3.89 & 0.31 \\
\hline To be depressed & 3.04 & 0.46 \\
\hline To be tensed & 2.95 & 0.81 \\
\hline To be lonely & 2.86 & 0.89 \\
\hline To be afraid & 3.88 & 0.33 \\
\hline To be give in & 2.92 & 0.82 \\
\hline \multicolumn{3}{|l|}{$\begin{array}{l}\text { Expectations related to the birth } \\
\text { experience }\end{array}$} \\
\hline Delivery to be dangerous & 3.95 & 0.21 \\
\hline \multicolumn{3}{|l|}{ Expectations related to the baby } \\
\hline Baby to stay in the room with me ${ }^{a}$ & 3.59 & 0.53 \\
\hline $\begin{array}{l}\mathrm{ECBE}=\text { Expectation of the } \mathrm{Ch} \\
\text { questionnaire. } \\
\text { aPositive item: the more positive } \\
\text { expectation. } \\
\mathrm{SD}=\text { Standard Deviation }\end{array}$ & Ex & $\begin{array}{l}\text { erience } \\
\text { ildbirth }\end{array}$ \\
\hline
\end{tabular}

Our study showed that expectations and experiences of birth in primiparas were different from multiparas women. It was evident that more items were experienced by women as they had expected (Table 4). Then, in each group only a few aspects of birth experiences were different from expectations.

Table 5 shows that most primiparas and multiparas women had negative expectations toward labor experience. Eighty two percent (246) of the primiparas and $71.7 \%$ (215) of the multiparas women scored $<90$, with a score range of 71 to 111 and 72 to 110 in the primiparas and multiparas. Comparison of the means of mother's expectation of labor between the two groups using Student's t-test demonstrated a statistically significant difference $(t=4.47, \mathrm{p}<0.003)$. Our findings also showed that $79.7 \%$ (239) of primiparas and $66.7 \%$ (200) of multiparas women had negative experience. Comparison of the means of mother's experience of labor between the two groups using independent Student's t-test demonstrated a statistically significant difference ( $\mathrm{t}=4.32, \mathrm{p}<0.003$ ). In the two groups, there was a negative significant relationship between the expectation and the experience of childbirth in primiparas $(r=-0.62, p<0.001)$ and multiparas $(r=-0.69$, $\mathrm{p}<0.001)$.

According to the results of our study, labor pain occurred as severe form of pain experienced by mothers with score of $\geq 8,76.3 \%$ (229) and $73.3 \%$ (220) in the primiparas and multiparas The means of pain scores were $(8.31 \pm$ 0.99 and $8.37 \pm 1.17)$, in the primiparas and multiparas. Compared to pain expected, pain at labor and delivery actually experiences was different. The means of pain scores were ( $6.28 \pm 0.49$ vs. $6.54 \pm 0.97)$, in both group. Comparison of expected and actual experienced pain scores between the two groups did not demonstrate any statistically significant differences $(p=0.06)$.

In the two groups, there was a significant relationship between expectation and intensity of labor pain experienced. The results showed that between negative expectation and pain there was a positive correlation $(r$ $=0.48, p<0.001)$ and $(r=0.50, p<0.001)$, in the primiparas and multiparas. However, when relationships were calculated for the positive expectation and pain, there were negative correlation $(r=-0.46, p<0.001)$ in primiparas and positive correlation $(r=0.44, p<0.003)$ in multiparas women. It shows that primiparas expected and experienced more negative emotion about labor pain. 
Table 4: Frequency Distribution of women in two group who experienced and not experienced each item $(\mathrm{n}=600)$

\begin{tabular}{|c|c|c|}
\hline Variables & Experienced N (\%) & Not Experienced N (\%) \\
\hline \multicolumn{3}{|l|}{ Primiparas } \\
\hline \multicolumn{3}{|c|}{ Expectations related to the overall birth experience } \\
\hline Wonderful & $130(43.5)$ & $170(56.5)$ \\
\hline Fearful & $263(87.6)$ & $37(12.4)$ \\
\hline Normal process & $277(92.3)$ & $23(7.7)$ \\
\hline Very long & $114(38)$ & $186(62.0)$ \\
\hline Full of surprises & $203(67.7)$ & $97(32.3)$ \\
\hline Safe & $143(47.7)$ & $157(52.3)$ \\
\hline Painful & 291(96.9) & $9(3.4)$ \\
\hline \multicolumn{3}{|c|}{ Expectations related to feelings during labor } \\
\hline \multicolumn{3}{|l|}{ Lonely } \\
\hline Strong & $232(77.4)$ & $68(22.6)$ \\
\hline Confident & $229(76.4)$ & $71(23.6)$ \\
\hline Afraid & $296(98.5)$ & $4(1.5)$ \\
\hline Very weak & 269 (76.9) & $31(23.1)$ \\
\hline Very safe & $236(78.5)$ & $64(21.5)$ \\
\hline Independent & $95(31.8)$ & $205(68.2)$ \\
\hline Depressed & $11(3.6)$ & $289(96.4)$ \\
\hline Tensed & $289(96.4)$ & $11(3.6)$ \\
\hline Delighted & $128(42.6)$ & $172(57.4)$ \\
\hline Give in & $51(16.9)$ & $249(83.1)$ \\
\hline Quiet & $40(13.3)$ & $260(86.7)$ \\
\hline Relaxed & $88(29.4)$ & $212(70.6)$ \\
\hline In pain & $10(33.3)$ & $200(66.7)$ \\
\hline Attached to the baby & $274(91.2)$ & $36(8.8)$ \\
\hline Proud & 294 (97.9) & $6(2.1)$ \\
\hline Expectations related to the birth & $62(20.5)$ & $238(79.5)$ \\
\hline Enjoyable & $106(35.4)$ & $194(64.6)$ \\
\hline Natural & $224(74.8)$ & $76(25.2)$ \\
\hline Baby's delivery to be understandable & $122(40.5)$ & $178(59.5)$ \\
\hline Delivery to be dangerous & $296(98.5)$ & $4(1.5)$ \\
\hline \multicolumn{3}{|l|}{ Expectations related to the baby } \\
\hline Baby to be healthy & $208(69.2)$ & $92(30.8)$ \\
\hline Baby to be beautiful & $122(40.5)$ & $178(59.5)$ \\
\hline Baby to stay in the room with me & $296(98.5)$ & $4(1.5)$ \\
\hline Baby to be harmed & $45(14.9)$ & $255(85.1)$ \\
\hline \multicolumn{3}{|c|}{ Expectations related to women's behavior when labor intensifies } \\
\hline Behave badly & $134(44.6)$ & $166(55.4)$ \\
\hline Lose control & $128(42.6)$ & $172(57.4)$ \\
\hline Cry & $299(99.5)$ & $1(0.5)$ \\
\hline Tolerate the intensity of labor & $95(31.8)$ & $205(68.2)$ \\
\hline Give inover body & $212(70.8)$ & $88(29.2)$ \\
\hline
\end{tabular}


Table 4 Continued

\begin{tabular}{|c|c|c|}
\hline Variables & Experienced N (\%) & Not Experienced N (\%) \\
\hline \multicolumn{3}{|l|}{ Multiparas } \\
\hline \multicolumn{3}{|c|}{ Expectations related to the overall birth experience } \\
\hline Wonderful & $74(24.6)$ & $226(75.4)$ \\
\hline Fearful & $274(91.2)$ & $26(8.8)$ \\
\hline Normal process & $289(96.4)$ & $21(3.6)$ \\
\hline Very long & $169(56.4)$ & $131(43.6)$ \\
\hline Full of surprises & $177(59.0)$ & $123(41.0)$ \\
\hline Safe & $283(94.3)$ & $17(5.7)$ \\
\hline Painful & $225(74.9)$ & $75(25.1)$ \\
\hline \multicolumn{3}{|c|}{ Expectations related to feelings during labor } \\
\hline Lonely & $163(54.4)$ & $137(45.6)$ \\
\hline Strong & $214(71.3)$ & $86(28.7)$ \\
\hline Confident & $289(96.4)$ & $11(3.6)$ \\
\hline Afraid & $144(48)$ & $156(52)$ \\
\hline Very weak & $72(24.1)$ & $228(75.9)$ \\
\hline Very safe & $23(7.7)$ & $277(92.3)$ \\
\hline Independent & $92(30.8)$ & $208(69.2)$ \\
\hline Depressed & $208(69.2)$ & $92(30.8)$ \\
\hline Tensed & $143(47.7)$ & $157(52.3)$ \\
\hline Delighted & $40(13.3)$ & $260(86.7)$ \\
\hline Give in & $6(2.1)$ & $294(97.9)$ \\
\hline Quiet & $17(5.6)$ & $283(94.4)$ \\
\hline Relaxed & $41(13.8)$ & $259(86.2)$ \\
\hline In pain & $206(68.6)$ & $94(31.4)$ \\
\hline Attached to the baby & $56(18.5)$ & $244(81.5)$ \\
\hline Proud & $103(34.4)$ & $197(65.6)$ \\
\hline \multicolumn{3}{|l|}{ Expectations related to the birth } \\
\hline Enjoyable & $122(40.5)$ & $178(59.5)$ \\
\hline Natural & $178(59.5)$ & $122(40.5)$ \\
\hline Baby's delivery to be understandable & $289(96.4)$ & $11(3.6)$ \\
\hline Delivery to be dangerous & $23(7.7)$ & $277(92.3)$ \\
\hline \multicolumn{3}{|l|}{ Expectations related to the baby } \\
\hline Baby to be healthy & $194(64.6)$ & $106(35.4)$ \\
\hline Baby to be beautiful & $226(75.4)$ & $74(24.6)$ \\
\hline Baby to stay in the room with me & 294 (97.9) & $6(2.1)$ \\
\hline Baby to be harmed & $57(18.9)$ & $243(81.1)$ \\
\hline \multicolumn{3}{|c|}{ Expectations related to women's behavior when labor intensifies } \\
\hline Behave badly & $57(27.7)$ & $243(72.3)$ \\
\hline Lose control & $206(68.7)$ & $94(31.3)$ \\
\hline Cry & $243(81.0)$ & $57(19.0)$ \\
\hline Tolerate the intensity of labor & $192(64.1)$ & 108 (35.9) \\
\hline Give inover body & $68(22.5)$ & $232(77.5)$ \\
\hline
\end{tabular}

Data are presented as percentage.

Values in this table are the frequency of each item in each group. 
Table 5: Distribution of mothers according to childbirth expectations and experiences level in the two group $(n=600)$.

\begin{tabular}{|c|c|c|c|}
\hline $\begin{array}{l}\text { Childbirth expectation } \\
\text { And experience level }\end{array}$ & Primiparas n (\%) & Multiparas n (\%) & P-value \\
\hline \multicolumn{4}{|l|}{ Expectation } \\
\hline Negative & $246(82)$ & 215 (71.7) & \multirow{3}{*}{$p<0.003^{*}$} \\
\hline Positive & $54(18)$ & $85(28.3)$ & \\
\hline Mean \pm SD & $82.8 \pm 7.8$ & $86.5 \pm 9.8$ & \\
\hline \multicolumn{4}{|l|}{ Experience } \\
\hline Negative & 239 (79.7) & $200(66.7)$ & \multirow{3}{*}{$p<0.003^{*}$} \\
\hline Positive & $61(20.4)$ & $100(33.3)$ & \\
\hline Mean \pm SD & $70.6 \pm 6.3$ & $79.5 \pm 9.9$ & \\
\hline
\end{tabular}

Data are presented as percentage.

Data compared by independent sample $t$ test.

${ }^{*} \mathrm{p}<0.05$.

Table 6: Correlation between 5 sub-items of women's expectation related to behavior during Pain intensity and labor Pain in The two groups $(n=600)$.

\begin{tabular}{lcccc}
\hline $\begin{array}{l}\text { Women's expectations } \\
\text { during labor intensify }\end{array}$ & \multicolumn{2}{c}{ Primiparas } & \multicolumn{2}{c}{ Multiparas } \\
\cline { 2 - 5 } behave in a bad way & $(\mathbf{r})$ & P-value & (r) & P-value \\
\hline lose control & 0.25 & $<0.001$ & 0.29 & $<0.003$ \\
\hline cry intensively & 0.28 & $<0.001$ & 0.31 & $<0.001$ \\
\hline bear and cope with pain & 0.35 & $<0.003$ & 0.36 & $<0.003$ \\
\hline give in over body & -0.18 & $<0.001$ & -0.35 & $<0.001$ \\
\hline
\end{tabular}

$r=$ Pearson's correlation coefficient.

Table 7: Sources of childbirth expectations information in the two groups $(n=600)$.

\begin{tabular}{|lrr|}
\hline Source of information & Primiparas N (\%) & Multiparas N (\%) \\
\hline Reading book, Internet, television & $33(11)$ & $25(8.3)$ \\
\hline Family and friends & $42(14)$ & $38(12.7)$ \\
\hline Mothers & $84(28)$ & $56(18.7)$ \\
\hline Family history of birth & $43(14.3)$ & $57(19)$ \\
\hline Antenatal classes & $15(5)$ & $32(10.7)$ \\
\hline Women's knowledge and beliefs & $27(9)$ & $31(10.3)$ \\
\hline Age life experience & $16(5.3)$ & $19(6.3)$ \\
\hline Midwives & $11(3.7)$ & $13(4.3)$ \\
\hline
\end{tabular}

Data are presented as percentage.

In this study, we also identified the relationship between the sub-items of expectations related to women's behavior when the labor pain intensified in both groups. The labor pain was positively correlated with the following items: behave in bad way and didn't act properly in labor due to unpleasant feeling related to delivery, loss of control, crying and give in control over her body and negatively correlated with the tolerance of the labor pain between two groups (Table 6).
Our observation from this research showed that $54.3 \%$ (164) of primiparas and $50.7 \%$ (178) of multiparas women before delivery didn't have enough information about the labor and delivery. There was no significant difference between two groups $(p=0.248)$. Also, only 9.7\% (29) participated in antenatal classes in both the groups. The findings of this study also provide information on what influenced a woman's beliefs in relation to childbirth and how they prepare for this 
event. The results showed that $28 \%$ (84) of primiparas achieved information through their mothers and in 19\% (57) of multiparas, source of information about childbirth was woman's family history of birth (Table 7).

\section{DISCUSSION}

Considering the main purpose of the present study, which was to compare the childbirth expectation and birth experience in primiparas and multiparas women, the results showed that the majority of participants had the negative expectation of childbirth which was more in primiparas than in multiparas. Primiparas expected a painful delivery, very long labor and fear of childbirth while in multiparas expectation of dangerous delivery, women feeling very week during labor and fear of labor were more important contributory factors in creating negative childbirth expectations. A study by Wijma et al. showed multiparas women expected less negative childbirth experience than primiparas ${ }^{28}$. In contrast, other studies had found that multiparas tended to report less positive expectations than primiparas ${ }^{15,22}$. The potential role of person's individual beliefs, perceptions, attitudes, and thoughts should not be ignored in relation to how they feel and behave in labor ${ }^{3}$. It seems that expectations differences between primiparas and multiparas can be attributed to the previous experience of giving birth in multiparas. This may suggest the effect of parity on the expectations.

It was found that a number of differences in expectations and experiences exist between both groups. Our results are consistent with the results of the study carried out by Ayers et $\mathrm{al}^{18}$. The findings of Stolte study showed that the labor and birth expectations were more different to the actual event in primiparas compared to multiparas ${ }^{12}$. This contradiction could be attributed to primiparas who had no experience to use for comparison. Also, multiparas have more knowledge and understanding of unexpected events than primiparas.

In some women, the existence of disparity between expectations and the actual experience of labor may be related to mother's unrealistic expectations about the childbirth experience. The differences may also be related to the maternity care and childbirth preparations between the two groups ${ }^{29}$. Heaman et al. found that women who attended antenatal classes had more positive expectations than those of women who did not attend $i^{30}$.

The findings of this study showed a significant association between expectations and experiences. Negative expectations were associated with a negative experience in both groups. Our findings are consistent with previous research in childbirth ${ }^{16}$. Most of negative expectations often achieved and experienced in women who expected them to happen. Furthermore, we found that due to unmet positive expectations related to childbirth some of women achieved no positive experience.

According to the results obtained in our study, there was a significant relationship between woman's expectations and actual experience of pain during labor. Women expressed that their labor pain was not as expected. They described that the pain they experienced was more than that anticipated. The degree of pain experienced during labor was unpredictable by both groups, which is inconsistent with the study carried out by Green ${ }^{10}$. It was somewhat surprising that multiparas did not have a more realistic expectation of labor pain even though they had previous experience of delivery. It shows that it is necessary to prepare women specifically being more realistic about labor pain.

The behavioral expectations of women during pain intensified play an important role on actual labor pain experience. To control their sense during actual childbirth experience, coping strategies used by women related to labor pain can help. The results of this study indicated that women who had negative expectation related to behaviors during pain intensity feel more severe pain. Insufficient information obtained about labor and behavioral control during labor is one of the important factors that cause a loss of confidence in women about childbirth ${ }^{12}$. In this study, majority of women did not have enough information thus affecting their expectation about behavior during labor. It should be noted that some women have unrealistic expectation about their ability to cope during labor. Therefore, inconsistencies between women's expectations and coping during labor may resolve by positive reinforcement of efforts to cope with labor pain ${ }^{11}$.

Study by Fenwick et al. indicated that the use of different sources to obtain information and knowledge about childbirth helped women to cope with the actual childbirth experience and influenced their childbirth expectations as well14.

Our findings showed that primary sources of information about childbirth were their mothers in primiparas and family history of birth in multiparas. The finding of others studies indicated that family, friends and internet were woman's primary sources of information about childbirth ${ }^{19,32}$. Midwives and 
antenatal classes as excellent sources of information were not considered by women. This finding is in agreement with another study ${ }^{19}$. Other study reported that the majority of women perceived midwifery care during childbirth as a good source of information ${ }^{31}$. Childbirth education classes can prepare women for unpleasant aspects of labor and birth. On the other hand, it can increase the sense of confidence in women for making decision and feeling the control of her labor by providing realistic and accurate information ${ }^{7}$, ${ }^{26}$. The women in this study felt that they were unable to control themselves due to inadequate knowledge about the realistic expectations.

The implications from this study support the need for an evaluation of the current preparation of women for childbirth. Women's individual needs can be significantly provided by maternity systems and health-care professionals. Educational programs are a contributory factor in increasing realistic knowledge to expectant mothers about what actually happens during labor.

Our findings suggest that assistance strategies may play a major role ito alleviate the labor pain in women who are afraid of this pain. Therefore, coping with labor pain in women can be achieved by participating in the childbirth preparation programs and the labor process.

To determine what the content of such a program should be and know the content should be presented to

\section{REFERENCES}

1. Blaaka G, SchauerEri T. Doing midwifery between different belief systems. Midwifery. 2008; 24(3):34452.

2. Beaton J, Gupton MA. Childbirth expectations: A qualitative analysis. Midwifery. 1990; 6(3): 133-9.

3. Highsmith, S. Primiparous' expectations of childbirth: The impact of consciousness. J PrenatPerinatPsychol Health. 2006; 21(2): 141-78.

4. Ulfsdottir H, Nissen E, Ryding EL, Lund-Egloff D, Wiberg-Itzel E. The association between labour variables and primiparous women's experience of childbirth; a prospective cohort study.BMC Pregnancy Childbirth. 2014; 14(208): 1-7.

5. Bhatt H, Pandya S, Kolar G, Nirmalan. PK. The Impact of Labour Epidural Analgesia on the Childbirth Expectation and Experience at a TertiaryCareCenter in Southern India.J Clin Diagn Res. 2014; 8(3): 73-6. the expectant mother is an important area for the future research.

\section{CONCLUSION}

The majority of women reported that they had a negative childbirth expectation and experience. Furthermore, they experienced more labor pain than expected. Expectations and experiences of birth were different in primiparas and multiparas women but further studies are required due to limited findings in this area of research.

In order to develop positive and realistic expectations of the actual childbirth experience, exploring women's expectations and ideas for childbirth are important. To assess childbirth expectation, we propose that the establishment of childbirth education classes by midwives can have a positive potential role on the birth experience of women.

\section{ACKNOWLEDGEMENT}

The authors would like to acknowledge the women for graciously sharing their thoughts and feeling regarding their birthing experiences. We wish also to sincerely thank the support of all the staff of Tabriz Nursing and Midwifery Faculty and all the colleagues in Alzahra Hospital.

\section{CONFLICTS OF INTEREST}

None of the authors have any conflicts of interest.

6. Oweis A. Jordanian mothers report of their childbirth experience: Finding from a questionnaire survey. Int J NursPract, 2009; 15(6): 525-33.

7. Ip WY, Chien WT, Chan CL. Childbirth expectations of Chinese first-time pregnant women. J Adv Nurs, 2003; 42(2): 151-58.

8. Soet JE, Brack GA, Dilorio C. Prevalence and predictors of women'sexperience of psychological trauma during childbirth. Birth. 2003; 30(1): 36-46.

9. Hodnett ED. Pain and women's satisfaction with the experience of childbirth: a systematic review. Am J Obstet Gynecol. 2002; 186(5): 160-72.

10. Green JM. Expectations and experiences of pain in labor: findings from a large prospective study. Birth. 1993; 20(2):65-72.

11. Hauck Y, Fenwick J, Downie J, Butt J. The influence of childbirth expectations on western Australian women's perceptions of their birth experience. Midwifery. 2007; 23(3): 235-47. 
12. Stolte K. Comparison of Women's Expectations of Labor with the Actual Event. Birth. 1987; 14(2): 99103.

13. Gibbins J, Thomson AM. Women's expectations and experiences of childbirth.Midwifery. 2001; 17(4): 30213.

14. Fenwick J, Hauck Y, Downie J, ButtJ. The childbirth expectations of a self-selected cohort of Western Australian women. Midwifery 2005; 21(1): 23-35.

15. Slade P, MacPherson S, Hume A, Maresh, $M$. Expectations, experiences and satisfaction with labour. Br J Clin Psychol. 1993; 32(4): 469- 83.

16. Green JM, Coupland VA, Kitzinger JV: Great Expectations: A prospective study of women's expectations and experiences of childbirth. 2nd ed. Cheshire, England: Books for Midwives Press; 1998. 260-1 p.

17. Gupton A, Beaton J, Sloan J, Bramadat I. The development of a scale to measure childbirth expectations.Can J Nurs Res. 1991; 23(2):35-47.

18. Ayers S, pickering AD. Women's expectation and experience of birth.Psychol Health.2005; 20: 79-92.

19. Oweis A, Abushaikha L. Jordanian pregnant women's expectations of their first childbirth experience. Int J NursPract. 2004; 10(6): 264-71.

20. Lowe NK. The nature of labor pain. Am J Obstet Gynecol. 2002; 18:16-24.

21. Change MY, Chen $\mathrm{SH}, \mathrm{Chen} \mathrm{CH}$. Factors related to perceived labor pain in primiparas. Kaohsiung J Med Sci. 2002; 18(12): 604-09.

22. Waldenstrom U, Borg IM, Olsson B, Skold M, Wall S. The childbirth experience: A study of 295 new mothers. Birth. 1996; 23(3): 144-53.
23. Fridh G, Gaston-Johansson F. Do primiparas and multiparas have realistic expectation of labor. ActaObstetGynecol Scand. 1990; 69: 103-09.

24. Christiaens W, Bracke P. Assessment of social psychological determinants of satisfaction with childbirth in a cross-national perspective. BMC Pregnancy Childbirth. 2007; 7(1): 1-12.

25. Christiaens W, Verhaeghe M, Bracke P. Childbirth expectations and experiences in Belgian and Dutch models of maternity care. J Reprod Infant Psych. 2008; 26(4):309-22

26. Gibbins J, Thomson AM. Women's expectations and experiences of childbirth.Midwifery.2001; 17:302-13.

27. Phumdoung S, Rattanaparikonn A, Maneechot K. pain during the first stage of labor. Songkla Med J 2004; 22(3):163-71.

28. Wijma K, Soderquist J, Wijma B. post-traumatic stress disorder after child birth: A cross sectional study. J AnxietyDisord1997; 11(6):587-97.

29. Skevington SM, Wilkes P. Choice and control: a comparative study of childbirth preparation classes. J Reprod Infant Psychol. 1992; 10(1):19-28.

30. Heaman M, Beaton J, Gupton A. A comparison of childbirth expectations in high risk and low risk pregnant women.ClinNurs Res. 1992;1(3): 252-65.

31. Tumblin A, Simkin P. Pregnant women's perception of their nurse's role during labor and delivery. Birth.2001; 28:52-6.

32. Martin DK, Bulmer SM, Pettker CM.Childbirth expectations and sources of information among low- and moderate-income nulliparous pregnant women.J Perinat Educ. 2013; 22(2):103-12. 